\title{
Correction to: Public Restrooms in Neighborhoods and Public Spaces: A Qualitative Study of Transgender and Nonbinary Adults in New York City
}

\author{
Samuel Dubin ${ }^{1}$ - Sari Reisner ${ }^{2,3}$ - Eric W. Schrimshaw ${ }^{4}$ - Asa Radix ${ }^{5}$ - Aisha Khan ${ }^{1}$ - Salem Harry-Hernandez ${ }^{1}$. \\ Sophia A. Zweig ${ }^{1} \cdot$ Liadh Timmins $^{1} \cdot$ Dustin T. Duncan ${ }^{1}$
}

Published online: 8 April 2021

๑) Springer Science+Business Media, LLC, part of Springer Nature 2021

\section{Correction to: Sexuality Research and Social Policy https://doi.org/10.1007/s13178-020-00504-3}

The original version of this article unfortunately a mistake.

The complete list of corrections is given below.

- The affiliation label for Liadh Timmins is now corrected in the author group

- Left column of p.2, first paragraph: The period should be placed after the reference citaiton "(GLOUCESTER COUNTY SCHOOL BOARD V. G.G, 2016; US Department of Education, 2016)"

- First paragraph under the header Procedure in p.3, [Blinded for Review] should be changed to NYU Langone Health

The original article has been corrected.

Publisher's Note Springer Nature remains neutral with regard to jurisdictional claims in published maps and institutional affiliations.

The original article can be found online at https://doi.org/10.1007/ s13178-020-00504-3

Dustin T. Duncan

dd3018@columbia.edu

1 Department of Epidemiology, Mailman School of Public Health, Columbia University, New York, NY, USA

2 Division of General Pediatrics, Boston Children's Hospital, Harvard Medical School, Boston, MA, USA

3 Department of Epidemiology, Harvard T.H. Chan School of Public Health, Boston, MA, USA

4 Department of Population Health Sciences, College of Medicine, University of Central Florida, Orlando, FL, USA

5 Callen-Lorde Community Health Center, New York, NY, USA 